\title{
Implementasi iLearning Terhadap Kualitas Pembelajaran Mahasiswa Studi Kasus:Universitas Banten Jaya
}

\author{
Mochamad Yusuf Romdoni ${ }^{1}$ \\ ${ }^{l}$ Dosen Fakultas Ilmu Komputer Universitas Banten Jaya \\ Jl. Ciwaru Raya No. 2, Kota Serang - Banten \\ Email: yusufromdoni@gmail.com
}

\begin{abstract}
ABSTRAK
iLearning merupakan suatu inovasi media pembelajaran yang mendukung kegiatan belajar mengajar dengan memanfaatkan media-media e-learning terpadu yang dapat saling terintegrasi dengan sistem Single Sign On (SSO) yaitu Rinfo, Rinfo Hangouts (RH), iMe serta berbagai aplikasi yang sudah berbasis clouds selain itu dikembangkan pula dashboard sistem yang memberikan informasi data statistik keaktifan mahasiswa sehinga sangat membantu dosen didalam membuat suatu keputusan. Pengembangan dashboard sistem iLearning Media menggunakan metode Waterfall sedangkan metode pengumpulan data yang digunakan dalam penelitian ini adalah studi literatur, observasi dan interview atau wawancara sesuai topik yang akan diambil setelah itu dilakukan pengujian terhadap kepuasan responden atas kualitas iLearning dengan menggunakan quisioner dengan skala likert. Untuk merancang dashboard sistem pada iLearning Media (iMe) ini digunakan metode perancangan struktural yaitu dengan menggunakan flowchart dan UML (Unified Modeling Language) didalam mendokumentasikan perangkat lunak dari sistem iLearning. Deangan adanya iLearning mahasiswa dapat lebih aktif, kreatif dan memiliki timbal balik yang kuat antara dosen dan mahasiswa, sehingga diharapkan kedepannya akan menghasilkan lulusan yang berkualitas dan menjadi sumber daya manusia yang handal serta mampu bersaing di era globalisaisi yang bercirikan teknologi informasi yang tinggi.
\end{abstract}

Kata kunci: Sistem, iLearning, Media

\section{ABSTRACT}

iLearning is an innovative media that support teaching and learning activities by making use of the media e-learning integrated system can be integrated with each other Single Sign On (SSO) is like Rinfo, Rinfo Hangouts (RH), IME as well as a variety of applications that have been developed based on the other clouds are also dashboard information systems that provide statistical data so that the students are very helpful liveliness lecturer in making a decision. ILearning Media dashboard development system using the Waterfall method while the data collection methods used in this research is the study of literature, observation and interview or interviews according topics that will be taken after it was examined to the satisfaction of respondents on quality iLearning using questionnaires with Likert scale. To design a system dashboard at iLearning Media (IME) is used method of structural design by using flowcharts and UML (Unified Modeling Language) for documentation in the software of the system iLearning. Wish that ILearning their students to be more active, creative and have a strong mutual between faculty and students, which is expected in the future will produce quality graduates and become skilled human resources and be able to compete in globalisaisi era characterized by high information technology.

Keywords: System, iLearning, Information, Media 


\section{PENDAHULUAN}

Universitas Banten Jaya adalah salah satu universitas yang hadir untuk memberikan kesempatan kepada lulusan SMA/sederajat yang terbaik untuk mendapatkan pendidikan dan keahlian di bidang Teknologi Informasi dan mendapat gelar tingkat sarjana (S1), Program ini dirancang untuk memenuhi kebutuhan terhadap tenaga-tenaga muda yang terampil dan profesional, terutama terkait dengan pengembangan, pemanfaatan, dan pengelolaan Teknologi Informasi dalam suatu pembelajaran yang saat ini semakin berkembang. Pendidikan yang saat ini sudah berjalan perlu untuk terus dikembangkan agar dapat meningkatkan efektifitas pembelajaran diantaranya belum mampu menghasilkan sumber daya manusia yang betul-betul siap dan ahli pada teknologi informasi yang semakin hari semakin berkembang dengan baik. Mengapa demikian karena hal ini terjadi kurangnya sistem pembelajaran yang dapat mendukung kualitas belajar mengajar yang baik dan juga efisien yang mengedepankan kemudahan dialam berinteraktif, berkomunikasi dan juga berkreasi tanpa selalu mengandalkan materi yang diperoleh didalam kelas saat jam mata kuliah.

Hal diatas dapat dijabarkan secara luas dengan memeprlihatkan adanya sistem pembelajaran yang masih bersifat konvensional dimana dosen hanya mampu memberikan materi pada power point dan juga papan tulis yang menuntut mahasiswa/i untuk terus terpaku pada materi yang disampaikan oleh dosen itu sendiri dan hal itu membuat mahasiswa/i cenderung merasa bosan dan akhirnya menjadi pasif padahal matakuliah yang berorientasi pada teknologi informasi meerupakan unsure pokok dasar yang teramat penting untuk membangkitakan semangat serta gairah mahasiswa didalam menyongsosng era globalisaisi saat ini yang sangat erat dengan teknologi komputer. Untuk mata kuliah yang berientasi pada teknologi informasi langsung hal ini dirasakan sangat kaku dan tidak optimal dimana hasil yang diperoleh tidak dapat memberikan peningkatan dan hasil apa-apa oleh mahasiswa itu sendiri dimana seharusnya untuk matakuliah yang berorientasi pada teknologi informasi mahsiswa/i seharusnya memperoleh pengalaman dan skill didalamnya sehingga kedepannya akan menambah wawasan dan kemampuan untuk mengenmbangkan potensi didalam diri mahasiswa untuk menjadi sumber daya manusia yang berkualitas memiliki energi dan daya saing yang positif untuk dapat bersaing dilapangan yang tidak akan lepas dengan pengaruh teknologi informasi komputer.

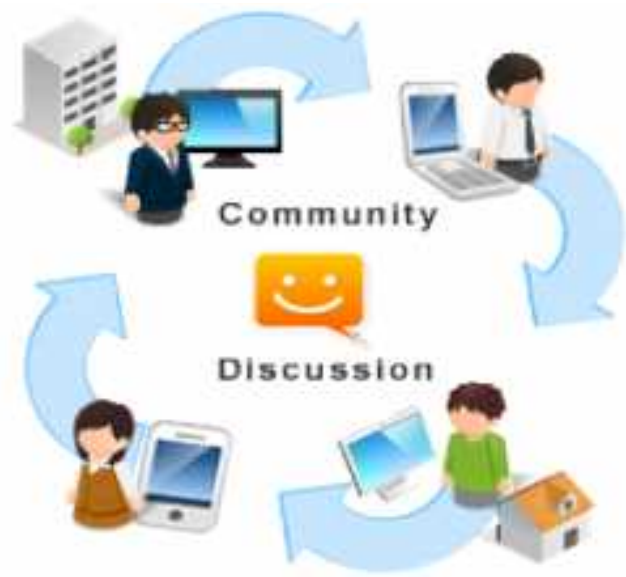

Gambar 1.1. Topologi E-Learning

Melihat latar belakang diatas dirasakan perlu adanya suatu inovasi perangkat pembelajaran yang berbasis elektronik yang dapat membangkitkan semangat aktifitas 
pembelajaran yang ada menjadi lebih baik, pembelajaran yang berbasis elektronik merupakan suatu inovasi yang dapat meningkatkan kualitas pembelajaran menjadi lebih mudah dan lebih efektif terhadap mahasiswa/i sehingga pembelajaran yang dilakukan dapat memberikan efek yang baik bagi perkembangan mahasiswa dan juga memberikan nilai tersendiri baik bagi dosen dan juga Universitas sebagai salah satu Universitas yang memiliki Fakultas Ilmu Komputer untuk mencetak lulusan yang memiliki softskill secara lugas dan kooperatif pada teknologi informasi komputer untuk memenuhi kebutuhan terhadap tenaga-tenaga muda yang terampil dan profesional di bidang Teknologi Informasi dimasyarakat.

\section{PERMASALAHAN}

Hadirnya teknologi informasi komputer mendorong setiap sumber daya ada untuk dapat mengerti didalam menjalani setiap proses bisnis dari berbagai kebutuhan dengan sempurna sehingga dapat berjalan dengan efektif dan juga efisien, sehingga dibutuhkan satu keahlian didalamnya untuk dapat melakukan itu semua dan tentu saja keahlian untuk memanfaatkan teknoogi informasi komputer yang tidak hanya sebatas teoritis tapi juga dengan wawasan yang lugas didalam memanfaatkanya cermat didalam menggunakannya dan juga kreatif. Untuk dapat menghasilkan suatu sumber daya manusia yang terampil didalam memanfaatkan teknologi informasi komputer saat ini tentu saja harus diawali dari pendidikan salah satunya dari Fakultas Ilmu Komputer yang menjadi mesin produksi untuk mencetak lulusan-lulusan yang berkualitas didalam mencetak sumber daya manusia yang profesioanl didalam memanfaatkan teknologi komputer dan namun apabila sistem pendidikan yang ada didalamnya tidak perkembang tentunya hal ini tidak sepadan dengan perkembangan teknologi informasi yang ada sekarang ini yang semakin hari semakin terus berkembang dengan pesat dan ini yang selama ini masih belum terdongkrak di Fakultas Ilmu Komputer di Universitas Banten Jaya dimana masih banyak dari setiap lulusan yang telah memperoleh gelar akademik komputer masih banyak tidak memiliki skill yang cukup untuk memanfaatkan teknologi informasi yang baik sesuai konsentrasinya dikarena sistem pembelajaran yang ada didalamnya masih sangat jauh tertinggal untuk meningkatkan potensi mahasiswa didalam memahami dan menguasai bidang ilmu yang diambil. Adapun masalah yang terjadi pada sistem pembelajaran di Universitas Banten Jaya khususnya pada Fakultas Ilmu Komputer saat ini yang dapat dirangkum oleh peneliti adalah :

1. Sistem pembelajaran yang saat ini berjalan masih berpotensi pasif terhadap respon mahasiswa dan juga dosen itu sendiri didalam menjalani kegiatan pembelajaran khususnya pada fakultas ilmu komputer.

2. Sistem pembelajaran yang tidak memiliki lahan yang dapat mendukung dosen dan mahasiswa untuk dapat berinteraksi dan menuangkan hasil kreasi dengan mudah.

3. Hadirnya sistem iLearning akan memeperbaiki sistem pembelajaran pada Fakultas Ilmu Komputer tertinggal jauh dengan perkembangan teknologi informasi saat ini yang mana masih berjalan satu aras dimana mahasiswa/i masih terpaku pada materi yang disampaikan oleh dosen didepan kelas tanpa diikuti peran teknologi informasi untuk membantu pembelajaran kepada mahasiswa sehingga hal ini akan seirama dengan teknologi saat ini.

4. Belum ada perangkat elektronik dalam membantu dosen dan mahiswa untuk menuangkan materi pembelajaran baik tugas matakuliah, karya ilmiah serta 
pengalaman pembelajaran untuk dapat dieksplor dengan baik kepada temanteman sekelas dan juga seluruh civitas di Universitas Banten Jaya.

5. Seberapa penting kualitas sistem pembelaran iLearning pada perkembangan mahasiswa itu sendiri didalam mengarungi bahtera teknologi informasi bagi perkembangan diri mereka.

6. Bagaimana mengetahui siswa yang aktif dalam mengikuti pelajaran sehingga dapat diukur efektivitas dari pembelajaran iLearning?

7. Bagaimana mendapatkan hasil tingkat kepuasan pemakai sistem informasi dengan bukti empiris?

8. Bagaimana mendapatkan hasil kualitas penilaian dari sistem dengan bukti empiris?

\section{LANDASAN TEORI DAN LITERATURE REVIEW}

\section{Landasan Teori}

- Definisi iLearning (integrated Learning)

Menurut Untung Rahardja [2011] ${ }^{(1)}$ iLearning adalah mengintegrasikan sumber daya dalam menjalankan dalam menjalankan Tri Dharma Perguruan Tinggi dengan menggunakan iPad, dimana iPad memiliki aplikasi pendukung pembelajaran dan masih banyak lainnya.Sistem iLearning yang ada sudah cukup baik, namun belum efektif dan beragam karena pelaksanaan ujiannya masih terpaku pada konsep paper based. Dengan menggunakan konsep computer based saat pelaksanaan ujian akan menentukan mutu kualitas dalam proses pembelajaran iLearning.

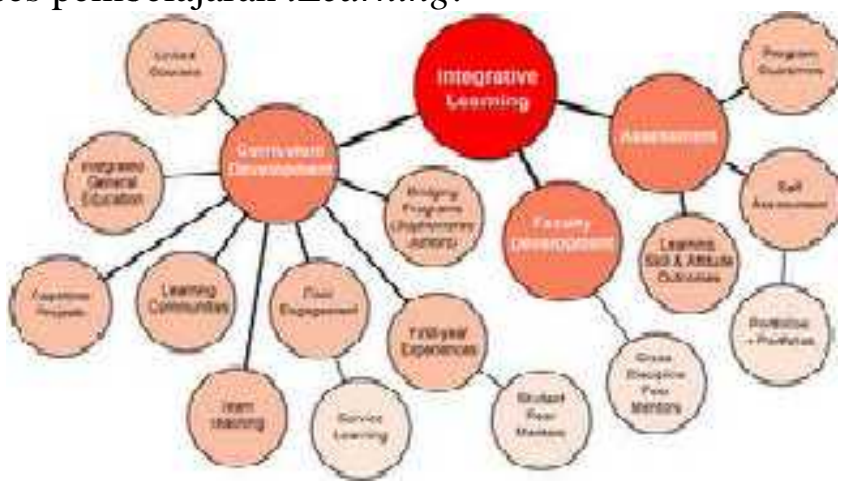

Gambar 2. TPi (Metode iLearning)

iLearning merupakan sebuah istilah e-Learning yang digunakan pada Perguruan Tinggi Raharja yang merupakan bagian dari Ten Pillar iLearning(TPi). Menurut Henderi et.al. (2013:333) mendefinisikan sistem iLearning sebagai sistem pembelajaran terpadu yang diterapkan merupakan salah satu bentuk untuk meningkatkan mutu menuju suatu pendidikan yang modern dan berkualitas.

Pembelajaran yang inovatif merupakan suatu hal yang sangat penting untuk kembangkan salah satunya dengan iLearning, menurut Henderi, dkk (2012) dalam penelitiannya yang berjudul Penggunaan Metode iLearning Untuk Meningkatkan Kualitas Pembelajaran Di Perguruan Tinggi menjelaskan bahwa iLearning merupakan suatu istilah yang diambil dari beberapa konsep hingga terbentuk istilah $4 \mathrm{~B}$, yaitu Belajar, Bermain, Bekerja, Berdoa. iLearning adalah suatu sistem untuk meningkatkan mutu menuju suatu pendidikan yang modern dan berkualitas agar proses belajar mengajar pun dapat berjalan dengan efisien dan efektif serta lebih terarah maka diperlukannya panduan pembelajaran ilearning. Sehingga proses belajar 
mengajar pun bisa berjalan dengan baik. adalah sistem pembelajaran terpadu yang diterapkan merupakan salah satu bentuk

- Definisi Kualitas Pembelajaran

Dalam kamus besar bahasa Indonesia (DEPDIKBUD, 1983:179) kualitas adalah ukuran baik buruk, mutu, taraf, kadar, atau derajat dari kecerdasan kepandaian dan sebagainya. Sedangkan menurut Nana Sudjana (1989:87) pengertian secara umum dapat diartikan suatu gambaran yang menjelaskan mengenai baik buruk hasil yang dicapai para siswa dalam proses pendidikan yang dismapaikan. Melalui pembelajaran akan terjadi proses pengembangan moral kegamaan, aktifitas, dan kreatifitas peserta didik melalui berbagai interaksi dan pengalaman belajar. Pembelajaran berbeda dengan mengajar yang mengajar yang pada prinsipnya menggambarkan aktifitas guru, sedangkan pembelajaran menggambarkan aktifitas peserta didik.

Ada dua segi umum tentang kualitas yang dijelaskan oleh (Ariani, 2004:3) yaitu, kualitas rancangan dankualitas kecocokan. Semua barang dan jasa dihasilkan dalam berbagai tingkatkualitas. Variasi dalam tingkat ini memang disengaja, Sedangkan Deming berpendapat Pengertian Definisi Kualitas adalah mempertemukan kebutuhan dan harapan konsumen secara berkelanjutan atas harga yang telah mereka.

Sedangkan delapan dimensi kualitas menurut Philip Kotler (2000:329-333) adalah sebagai berikut :

1) Kinerja (performance): karakteristik operasi suatu produk utama,

2) Ciri-ciri atau keistimewaan tambahan (feature),

3) Kehandalan (reliability): probabilitas suatu produk tidak berfungsi atau gagal,

4) Kesesuaian dengan spesifikasi (conformance to specifications),

5) Daya Tahan (durability),

6) Kemampuan melayani (serviceability)

7) Estetika (estethic): bagaimana suatu produk dipandang dirasakan dan didengarkan, dan

8) Ketepatan kualitas yang dipersepsikan (perceived quality).

Beberapa definisi kualitas berdasarkan konteksnya perlu dibedakan atas dasar: organisasi, kejadian, produk, pelayanan, proses, orang, hasil, kegiatan, dan komunikasi (Dale, 2003:4).

Seperti dikatakan oleh Sutikno (2007) dalam C.I. Yogihati (2010) menyatakan :

"Bahwa pencapaian kualitas pembelajaran merupakan tanggung jawab seorang guru dan dosen melalui penciptaan pengalaman belajar yang bermakna bagi siswa atau mahasiswa dan fasilitas yang didapat siswa atau mahasiswa untuk mencapai hasil belajar yang maksimal".

Pembelajaran bermakna merupakan suatu pendekatan dalam pengelolaan sistem pembelajaran melalui cara-cara belajar yang aktif menuju belajar yang mandiri. Kemampuan belajar mandiri merupakan tujuan akhir dari pembelajaran bermakna. Untuk dapat mencapai hal tersebut, kegiatan perkuliahan dirancang sedemikian rupa agar bermakna bagi mahasiswa. Belajar bermakna terjadi bila mahasiswa berperan aktif dalam proses belajar dan akhirnya mampu memutuskan apa yang akan dipelajari dan cara mempelajarinya (Yamin, 2007). 
Istilah pembelajaran kembali dijelaskan juga oleh Yogihati (2010) dalma sebuah jurnal nasional yaitu :

"Pembelajaran bermakna berguna untuk menumbuhkan kemampuan belajar aktif pada diri mahasiswa dan menggali kemampuan mahasiswa serta dosen untuk bersamasama berkembang dalam berbagai pengetahuan keterampilan dan pengalaman. Melalui belajar bermakna mahasiswa diharapkan akan lebih mampu mengenal dan mengembangkan semua pengetahuan yang dimilikinya. Di samping itu, mahasiswa juga secara penuh menyadari akan pentingnya menggunakan berbagai sumber belajar yang terdapat di sekelilingnya, mendorong mahasiswa untuk berprakarsa, berpikir secara sistematis, kritis, tanggap, sehingga dapat menyelesaikan masalah dalam kehidupan sehari-hari melalui pencarian informasi yang berguna bagi dirinya”.

Dari sisi media belajar kualitas dapat dilihat dari seberapa efektif media belajar digunakan oleh guru untuk meningkatkan intensitas belajar siswa. Dari sudut fasilitas belajar kualitas dapat dilihat dari seberapa kontributif (memberi sumbangan) fasilitas fisik terhadap terciptanya situasi belajar yang aman dan nyaman. Sedangkan dari aspek materi, kualitas dapat dilihat dari kesesuainnya dengan tujuan dan kompetensi yang harus dikuasi siswa.

Jadi kualitas pembelajaran merupakan suatu ukuran atau penilaian yang ditujukan terhadap suatu pendidikan yang di berikan atau di peroleh tenaga pendidik dan peserta didik melalui metode, fasilitas serta sarana dan prasarana pembelajaran sehingga menghasilkan timbal balik yang baik bagi mereka dan juga pihak penyelenggara pendidikan.

\section{Literature Review}

Banyak penelitian yang sebelumnya (literature review) dilakukan mengenai pembahasan tentang penyusunan jadwal rencana studi atau yang lebih banyak dikenal sebagai pengisian KRS (Kartu Rencana Studi) berbasis online pada dunia pendidikan saat ini.Dalam melakukan pengembangan OJRS+ ini perlu dilakukan studi pustaka untuk dijadikan sebagai bahan acuan untuk memperkuat hasil penelitian dengan cara mengindentifikasikan metose yang pernah dilakukan, mengembangkan penelitian sebelumnya yang memiliki korelasi yang seimbang dengan implementasi sistem iLearning di Universitas Banten Jaya. Beberapa literature review yang didapakan diantaranya adalah sebagai berikut :

1. "Penggunaan Metode iLearning Untuk Meningkatkan Kualitaas Pembelajaran di Perguruan Tinggi", Oleh Henderi, dkk dari CCIT Journal Perguruan Tinggi Raharja (Henderi, dkk 2013) menerangkan bahwa Sistem iLearning adalah sistem pembelajaran terpadu yang diterapkan merupakan salah satu bentuk untuk meningkatkan mutu menuju suatu pendidikan yang modern dan berkualitas. Alasan penerapan metode pembelajaran iLearning ini yaitu berharap dapat memberikan sistem pembelajaran yang lebih aktif dan memiliki timbal balik yang kuat antara dosen dan mahasiswa, karena proses belajar mengajar yang inovatif dan efisien tentunya akan menambah kesenangan dan semangat para mahasiswa/i sehingga mahasiswa/i pun tidak akan merasa jenuh dan pasif.

2. "iLearning : concept and applications" adalah judul dari penelitian yang dilakukan oleh Soekartawi (2002b). iLearning dapat dilihat dari perspektif yang berbeda. Hal ini mengacu pada istilah generic untuk semua didukung tekhnologi pembelajaran 
menggunakan sebuah array dari mengajar dan belajar alat-alat sebagai ponsel menjembatani, audio dan kaset video, telekonferensi, transmisi satelit, dan pelatihan berbasis web lebih diakui atau computer dibantu instruksi juga sering disebut sebaga online program. iLearning berkembang sangat cepat karena keuntungan yang cepat dari transformasi digital global di sektor pendidikan.

3. "Implementasi iLearning Media Dalam Mendukung Sistem Pemblejaran iLearning Pada Perguruan Tinggi Raharja", Oleh Untung Raharja, dkk dari CCIT Journal Perguruan Tinggi Raharja (Untung Raharja, dkk, 2014) menerangkan bahwa Untuk mendukung agar sistem pembelajaran dapat lebih menarik adalah dengan memanfaatkan teknologi informasi yang ada. iLearning adalah metode perkuliahan di Perguruan Tinggi Raharja yang menggunakan media iPad untuk mempermudah proses pembelajaran mahasiswa. Dengan adanya metode ini maka mahasiswa dapat belajar, bekerja, berdoa dan bermain dengan iPad. Istilah tersebut dikenal dengan nama 4B. iLearning Media atau disingkat dengan nama iMe adalah aplikasi berupa site yang dibuat dan dapat digunakan oleh seluruh mahasiswa Perguruan Tinggi Raharja untuk mengeksplor kreativitasnya dalam belajar. Ini merupakan sistem pembelajaran online yang memudahkan mahasiswa dalam belajar, karena dapat dilakukan di manapun dan kapanpun.

4. Penelitian yang dilakukan oleh Rano Kurniawan, dkk di Perguruan Tinggi Raharja pada tahun 2012 dengan judul "Penggunaan Ipad Mendukung Pembelajaran Pada Mahasiswa iLearning" menjelaskan bahwa untuk mendukung keefektifan metode pembelajaran iLearning diperlukan adanya sarana pendukung sebagai standarisasi. Didalam iPad terdapat aplikasi yang menudkung kegiatan iLearning. Dengan adanya iad, hal ini dapat memudahkan pembelajaran iLearning serta dapat menciptakan integritas yang baik untuk metode pembelajaran. Melalui satu sentuhan mahasiswa dapat menjelajah berbagai hal, sehingga tercipta jiwa iLearning dan ilmu pengetahuan yang dapat diserap secara efektif dan efisien sehingga mahasiswa memiliki kemampuan lebih dan selalu up to date dengan perkembangan ilmu pengetahuan maupun teknologi yang baru.

5. Guo-Heng Luo, Eric Zhi-Feng Liu, Hung-Wei Kuo, Shyan-Ming Yuan (2014) dalam penelitiannya yang berjudul "Design and Implementation of a SimulationBased Learning System for International Trade". In the traditional instructional method used in international trade, teachers provide knowledge to learners by lecturing using slides and setting assignments; however, these methods merely deliver international trade knowledge rather than facilitating student development of relevant skills. To solve these problems, we proposed a simulationbased learning system for international trade, combining international trade-process simulation and business letter writing. We investigated learner opinions toward the system and the quality of business letters by using quantitative and qualitative analyses. Regarding the results, learners perceived that the proposed system improved their knowledge of international trade and business English.

6. Salem Alkhalaf, Steve Drew, Rayed Alghamdi, Osama Alfarraj (2012) dalam penelitiannya yang berjudul "E-learning system on higher education institutions in KSA: attitudes and perceptions of faculty members". This paper presents findings from a study evaluating eLearning systems in the Kingdom of Saudi Arabia (KSA). E-Learning Systems are a technological development that have reformed and restructured the delivery and interaction of students and teachers with course materials and related resources. E-Learning systems have been widely used in developed countries and have recently become more popular in many developing countries. To date, however, little attention has been paid to the issue of measuring 
the impact of eLearning on academic staff at higher educational institutions in the Kingdom of Saudi Arabia. Responding to this gap in the literature, this study investigates the impact of e-Learning systems in higher education institutions in this context. A survey based on the IS Success/Impact Measurement Framework was executed in a sample population of faculty members using e-Learning in two top universities in the KSA. The findings of this study show positive academics' attitudes towards eLearning systems in higher education, helping faculty members to improve their job performance, and educational organizations to provide better and new products and services to users.

7. L. Jegatha Deborah, R. Baskaran, A. Kannan (2012) dalam penelitiannya yang berjudul "Learning styles assessment and theoretical origin in an E-learning scenario: a survey". The performance of the learners in E-learning environments is greatly influenced by the nature of the posted E-learning contents. In such a scenario, the performance of the learners can be enhanced by posting the suitable E-learning contents to the learners based on their learning styles. Hence, it is very essential to have a clear knowledge about various learning styles in order to predict the learning styles of different learners in E-learning environments. However, predicting the learning styles needs complete knowledge about the learners past and present characteristics. Since the knowledge available about learners is uncertain, it can be resolved through the use of Fuzzy rules which can handle uncertainty effectively. The core objective of this survey paper is to outline the working of the existing learning style models and the metrics used to evaluate them. Based on the available models, this paper identifies Felder-Silverman learning style model as the suitable model for E-learning and suggests the use of Fuzzy rules to handle uncertainty in learning style prediction so that it can enhance the performance of the E-learning system.

\section{Pemecahan Masalah}

Penelitian ini menggunakan metode deskriptif dengan pendekatan Survey. Metode Deskriptif merupakan Suatu metode dalam meneliti status sekelompok manusia, suatu objek, suatu set kondisi, suatu sistem pemikiran ataupun suatu kelas peristiwa pada masa sekarang. Untuk data-data diperoleh dari sejumlah responden dengan menggunakan Kuesioner terhadap mahasiswa di Universitas Banten Jaya yang mengikuti pembelajaran dengan iLearning.

Metode deskriptif tidak hanya terbatas pada pengumpulan data, tetapi meliputi analisis dan interprestasi tentang arti data itu. Penelitian deskriptif membandingkan persamaan dan perbedaan fenomena tertentu (Winarno Surachmad, 1980, h. 139). Selain itu dipergunakan metode survey pada waktu pengumpulan data dengan teknik korelasional.

Penelitian ini akan menjelaskan bentuk aktifitas atau kegiatan proses pembelajaran untuk mengetahui kualitas serta efektivitas pembelajaran dengan implementasi sistem iLearning. Data-data diperoleh dari sejumlah responden dengan menggunakan kuesioner kepada mahasiswa yang telah melaksanakan proses pembelajaran dengan iLearning.

\subsection{Populasi dan Sampel}

Populasi merupakan Jumlah keseluruhan unit analisis yang akan diselidiki karakteristik atau ciri-cirinya, sedangkan Sampel merupakan bagian dari populasi yang dapat mewakili karakteristik dari populasi. 


\subsubsection{Populasi}

Yang menjadi populasi penelitian ini adalah Mahasiswa yang teridir dari lakilaki dan juga perempuan, Mahasiswa yang dimaksud adalah Mahasiswa-mahasiswa di Universitas banten Jaya yang masih aktif kuliah dari Fakultas Ilmu Komputer yang tergabung dalam kelas yang mengikuti mata kuliah Jaringan Komputer \& Komunikasi di Universitas Banten jaya. Jumlah mahasiswa yang tercatat aktif pada saat ini ada 60 orang.

\subsubsection{Sampel}

Pengambilan sampel dapat digunakan dengan pendekatan "Sample Random Sampling" Perhitungan jumlah sampel dari populasi yang berdistribusi normal dapat dilakukan dengan metode pemilihan sampel dengan rumus Slovin, sebagai berikut :

$$
n=\frac{N}{\left(1+N \cdot e^{2}\right)}
$$

\section{Dimana :}

$\mathrm{n}=$ ukuran Sampel

$\mathrm{N}=$ ukuran populasi

$\mathrm{e}^{2}=$ Persen kesalahan yang diinginkan atau ditolerir (digunakan sebesar $10 \%$ )

Dengan menggunakan rumus Slovin tersebut, maka penelitian ini dari sampel mahasiswa sebanyak:

$$
\begin{aligned}
& n=\frac{\mathrm{N}}{\left(1+\mathrm{N} \cdot \mathrm{e}^{2}\right)} \\
& n=\frac{60}{\left(1+60 .(0,1)^{2}\right)} \\
& n=\frac{60}{(1+0,6)} \\
& n=\frac{60}{(1.06)} \\
& n=38
\end{aligned}
$$

Jumlah sampel jika mengikuti aturan rumus Slovin dari total populasi $(\mathrm{N}=$ 60orang) akan menghasilkan sampel Minimum sebesar 38 orang.

\subsection{Instrumen Penelitian}

Penelitian ini menggunakan instrumen Kuesioner yang dibuat dengan menggunakan closed questions. Dengan menggunakan closed questions, responden dapat dengan mudah menjawab kuesioner dan data dari kuesioner itu dapat dengan cepat dianalisis secara statistik, serta pernyataan yang sama dapat diulang dengan mudah.

Kuesioner berisikan pertanyaan-pertanyaan terstruktur yang berkaitan dengan permasalahan dalam penelitian implementasi sistem iLearning Media. Kuesioner ini nantinya akan disebarkan kepada responden atau objek yang menjadi pusat penelitian yaitu para pelajar di Universitas Banten Jaya pada Fakultas Ilmu Komputer Tahun Ajaran 2015-2016. 
Variabel adalah sesuatu yang menjadi objek atau sering juga disebut sebagai faktor yang berperan dalam peristiwa atau gejala yang akan diteliti. Dalam penelitian ini ada dua variabel, yang masing-masing dari variabel tersebut merupakan bagian dari variabel bebas (Independent Variable) dan variabel terikat (Dependent Variable). Untuk variabel bebas dalam penelitian ini adalah Kualitas Penilaian, sedangkan variabel terikatnya adalah Efektivitas Pembelajaran.

Kuesioner yang akan dirancang dalam penelitian survei ini akan menggunakan tipe skala likert. Menurut Sudaryono et.al. (2013:49) Skala Likert digunakan untuk mengukur sikap, pendapat dan persepsi seseorang atau sekelompok tentang kejadian atau gejala sosial. Dalam penelitian gejala sosial telah ditetapkan secara spesifik oleh peneliti, yang selanjutnya disebut sebagai variabel penelitian. Dengan menggunakan skala likert, maka variabel yang akan diukur dijabarkan menjadi dimensi, dimensi dijabarkan menjadi sub-variabel kemudian sub variabel dijabarkan lagi menjadi indikator-indikator yang dapat diukur. Akhirnya indikator-indikator yang terukur ini dapat dijadikan titik tolak untuk membuat item instrumen yang berupa pertanyaan atau pernyataan yang perlu dijawab oleh responden.

\subsection{Desain Penelitian}

Menurut Hasibuan (2007:62) "Metode penelitian atau desain penelitian merupakan bagian dari metodologi. Metodologi penelitian bisa digunakan ke berbagai macam riset desain. Ada beberapa macam desain penelitian yang bisa kita pilih sesuai dengan penelitian yang ingin kita lakukan, antara lain metode correlational, metode causal comperative, metode experimental, metode ethnographic yang biasanya digunakan dalam bidang sosial, metode historica research, metode survey dan ada juga action research dimana penelitian ini para penelitinya terlibat langsung di dalamnya, penelitian ini biasanya digunakan dalam penelitian bidang sosial. Dalam bidang ilmu teknologi informasi desain penelitian yang paling banyak digunakan adalah desain eksperimental dan studi kasus (case study)".

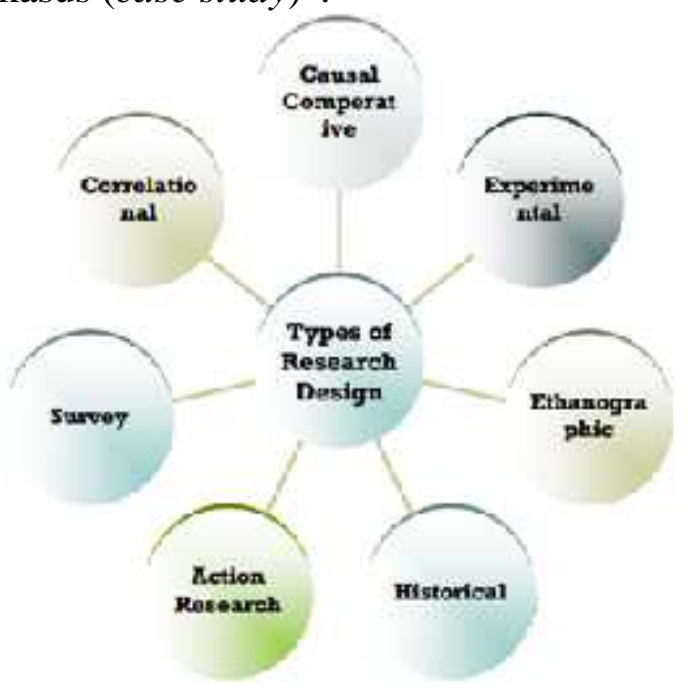

Gambar 3.1. Macam-macam Desain Penelitian

Sumber: Zainal A Hasibuan, Metodologi Penelitian pada Bidang Ilmu Komputer dan Teknologi Informasi (2007:61) 
Berdasarkan pada gambar 3.1. dan dari metode penelitian yang telah ditetapkan maka dapat disimpulkan bahwa penelitian ini akan menggunakan desain penelitian survei (Survey Research). Kemudian untuk melengkapi penelitian survei ini digambarkanlah desain penelitian dalam bentuk hierarki pada gambar 3.2. berikut ini:

\subsection{Teknik Pengumpulan Data}

Dalam pembuatan proposal penelitian ini yang berjudul: Pengaruh Pembelajaran iLearning Terhadap Kualitas Pembelajaran dan Persepsi Mahasiswa di Universitas Banten Jaya, penulis melakukan beberapa metode pengumpulan data. Beberapa metode tersebut dijelaskan dibawah ini.

\subsubsection{Metode Observasi (Pengamatan)}

Merupakan cara pengumpulan data dimana peneliti tidak memiliki kendali sama sekali terhadap pemunculan respon objek yang diamati, kecuali dalam menentukan faktor yang diamati dan memeriksa ketelitian data. Penelitian dilaksanakan langsung ke kampus Universitas Banten Jaya Kota Serang yang menjadi lokasi penelitian guna memperoleh data dan keterangan.

\subsubsection{Metode Wawancara}

Metode ini dilakukan melalui proses tanya jawab dengan beberapa narasumber di tempat atau lokasi dimana objek penelitian dilakukan. Proses tanya jawab ini dilakukan langsung kepada Mahasiswa selaku responden di kampus Universitas Banten Jaya dan juga dosen yang sudah melihat dan mengamati pembelajaran iLearning ini.

\subsubsection{Studi Kepustakaan}

Untuk memperoleh definisi yang valid serta dapat membantu didalam melengkapi laporan penelitian yang baik maka dibutuhkan suatu metode untuk mendapatkan informasi dan data dari berbagai sumber (literatur) seperti buku-buku, jurnal-jurnal atau literatur lain yang diperlukan untuk kebutuhan penganalisaan responden pengguna Sistem iLearning.

\subsubsection{Kuesioner}

Adalah metode untuk mendapatkan informasi dan data dari pendapat/opini masyarakat (dalam hal ini mahasiswa sebagai pengguna sistem iLearning) yang diambil secara bersamaan pada waktu yang telah ditentukan. Untuk dapat mewujudkan data segera terkumpul, maka dibutuhkan strategi dalam teknik pengumpulan data.

\subsubsection{Strategi}

Selama menyusun penelitian telah dilakukan implementasi yang terdiri dari 12 strategi sehingga memperoleh hasil penelitian yang optimal terhadap projek

Tabel 3.7. Strategi implementasi sistem

\begin{tabular}{|l|c|l|}
\hline No. & Strategi & \multicolumn{1}{|c|}{ Keterangan } \\
\hline 1 & UBJSTR01 & $\begin{array}{l}\text { Memiliki kelas KBM dengan total jumlah mahasiswa dari } \\
\text { seluruh kelas minimal 50 orang. }\end{array}$ \\
\hline 2 & UBJSTR02 & Terdapat 50 Mahasiswa registrasi Rinfo. \\
\hline 3 & UBJSTR03 & Terdapat 50 Mahasiswa terdaftar di milis. \\
\hline 4 & UBJSTR04 & Terdapat 60 topic balasan di milis class \\
\hline 5 & UBJSTR05 & Terdapat 50 Mahasiswa posting cermi tentang pengalaman \\
\hline
\end{tabular}




\begin{tabular}{|l|l|l|}
\hline 6 & UBJSTR06 & $\begin{array}{l}\text { Terdapat 50 Mahasiswa sudah memiliki Gravatar di iMe } \\
\text { (unbaja.ilearning.me) }\end{array}$ \\
\hline 7 & UBJSTR07 & $\begin{array}{l}\text { Terdapat 50 Mahasiswa sudah membuat poto profile di Milis } \\
\text { Class disertai cermi tutorialya }\end{array}$ \\
\hline 8 & UBJSTR08 & $\begin{array}{l}\text { Terdapat 50 Mahasiswa sudah membuat SKUP pada iMe } \\
\text { unbaja.ilearning.me }\end{array}$ \\
\hline 9 & UBJSTR09 & $\begin{array}{l}\text { Terdapat 50 Mahasiswa menyelesaikan soal dengan Standar } \\
\text { Jawaban di iMe }\end{array}$ \\
\hline 10 & UBJSTR10 & $\begin{array}{l}\text { Terdapat 50 Mahasiswa posting cermi tentang Wirless Router } \\
\text { dengan cara embed tutorial docs/ slides ke iMe. }\end{array}$ \\
\hline 11 & UBJSTR11 & $\begin{array}{l}\text { Terdapat 50 video Tutorial Disiplin IT Pada Jaringan Komputer } \\
\text { dan Komunikasi Data }\end{array}$ \\
\hline 12 & UBJSTR12 & Terdapat 500 Posting Cermi di iMe Unbaja \\
\hline
\end{tabular}

\section{Use Case Diagram}

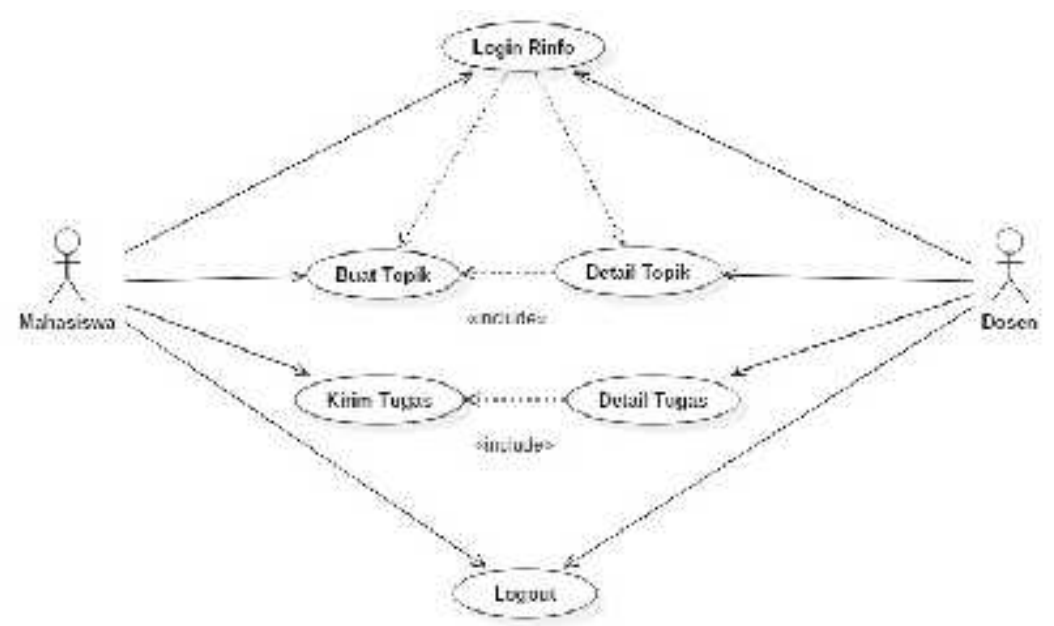

Gambar 4.22 Use Case Diagram Proses Rinfo di iLearning

Use Case diatas mahasiswa dan dosen membuat suatu topik didalam suatu milis class dengan menggunakan Rinfo sebagai awalnya, topic diatas akan dijadikan suatu diskusi secara online. 


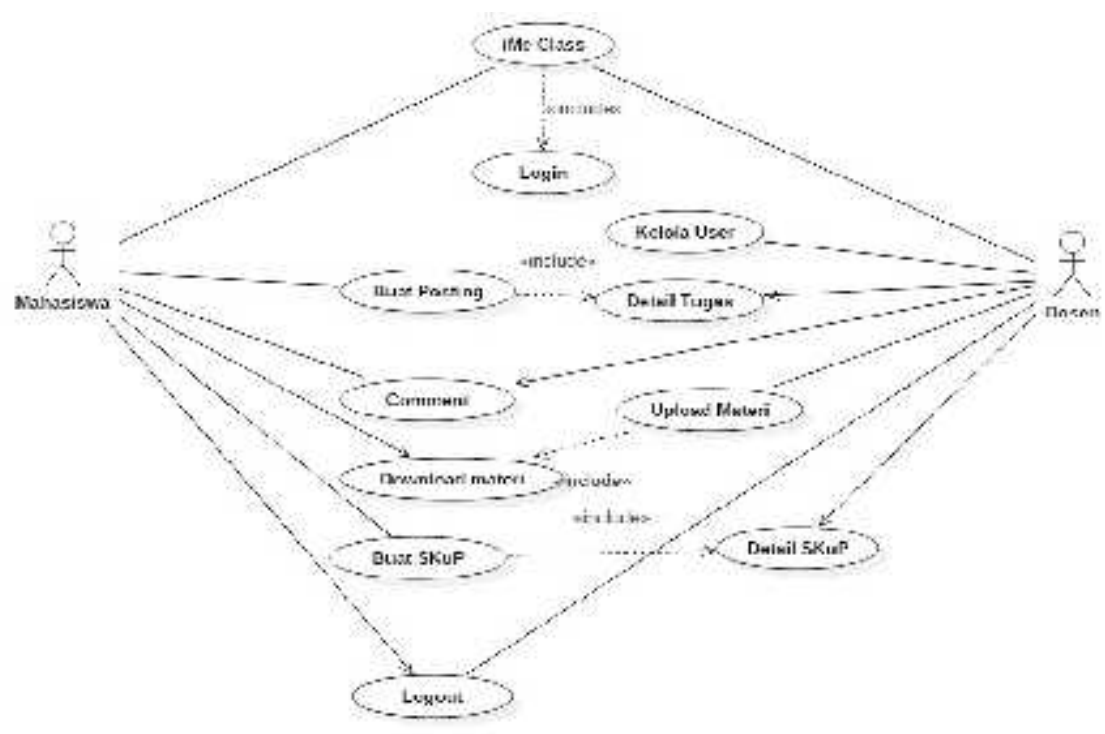

Gambar 4.3 Use Case Diagram Proses iMe (iLearning Media)

Use Case diatas mahasiswa dan dosen membuat suatu posting baik materi dan juga tugas didalam iMe Class ini juga terdapat comment dari kedua belah pihak untuk memperlihatkan adanya komunikasi dan interaksi.

\section{Flowchart}

Berikut ini adalah flowchart program yang menjelaskan prosedur serta alur dari sistem iLearning yang diterapkan di Universitas Banten Jaya, flowchart ini dibuat terpisah-pisah berdasarkan masing-masing prosedur dan proses yang terjadi di dalam iLearning.

1. Registrasi Rinfo

Flowchart ini menjelaskan proses registrasi rinfo dari mahasiswa yang akan mulai memasuki sistem iLearning . 


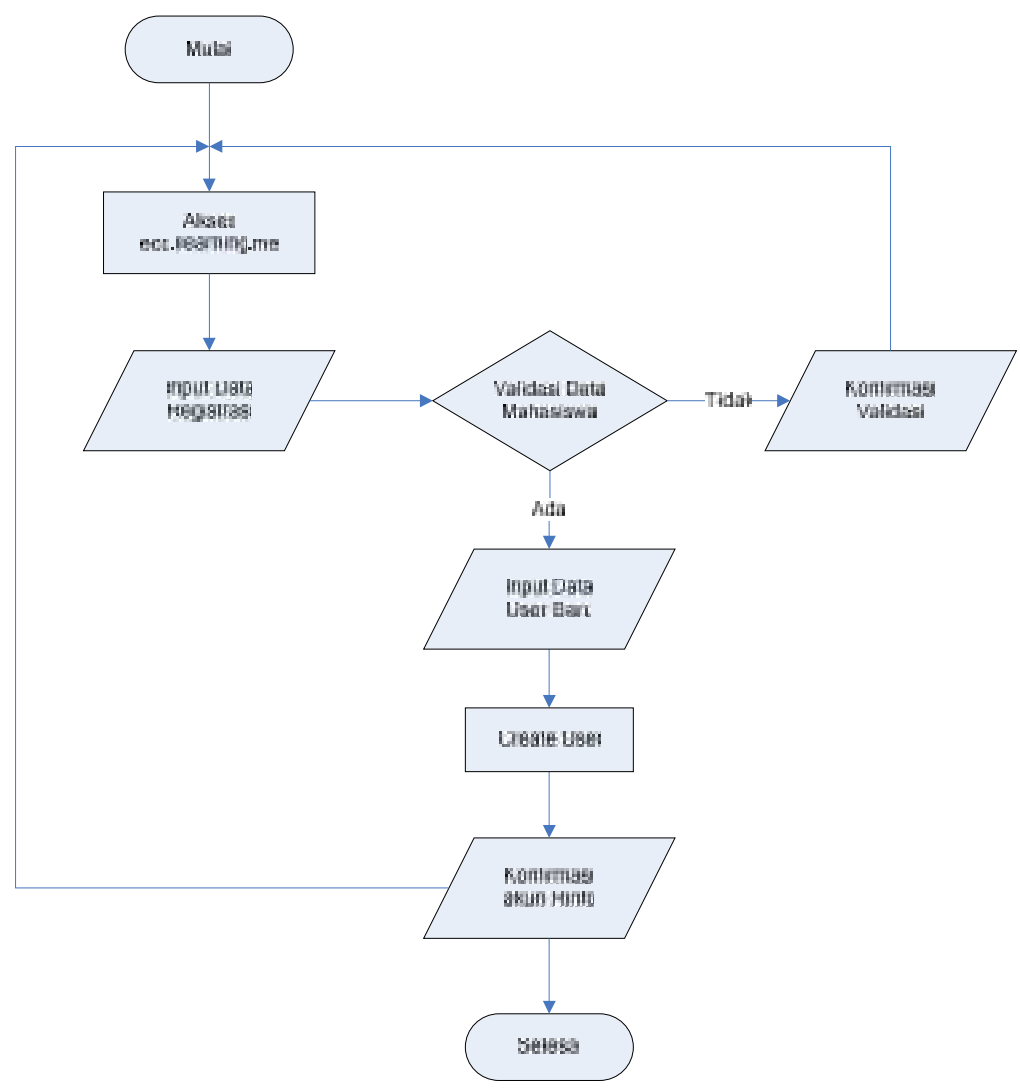

Gambar 4.2

Flowchart Program Registrasi Rinfo Mail

\section{Request Milis Class}

Flowchart ini menjelaskan tahapan request yang dilakukan mahasiswa mengunakan rinfo mail untuk dapat bergabung ke dalam milis class yang dibuat oleh dosennya. 


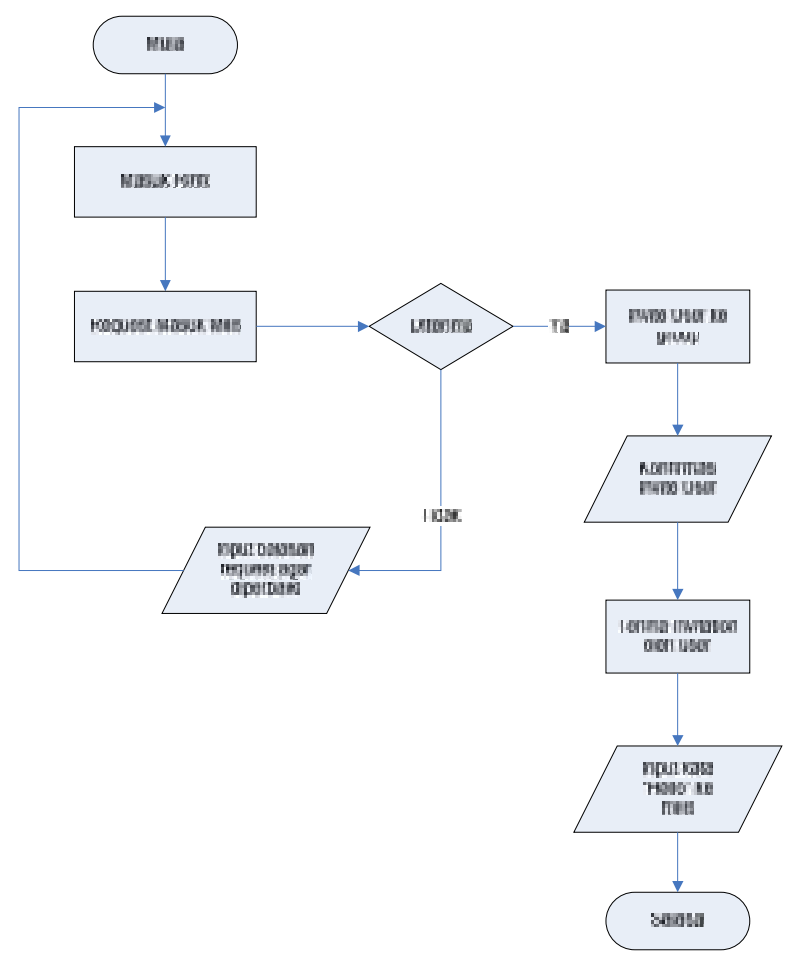

Gambar 4.4

Flowchart Program Masuk Milis Class

4. Request Author di iMe Class

Flowchart ini menjelaskan tahapan untuk menjadi author di iMe Class yang sudah disediakan oleh dosen, tentunya yang dilakukan mahasiswa mengunakan rinfo untuk dapat bergabung ke dalam iMe class ini. iMe ini nantinya akan menjadi wadah bagi mahasiswa untuk dapat menulis cerita sebagai salah satu syarat menuangkan tugasnya. 


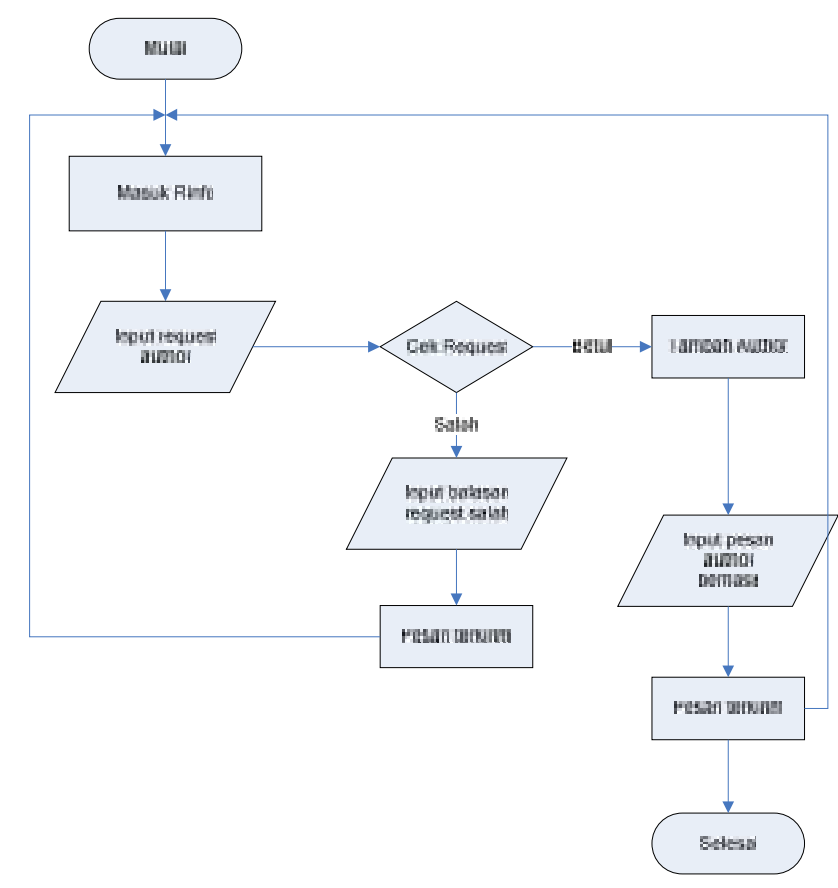

Gambar 4.5

Flowchart Program Request Author di iMe

5. Membuat Materi.

Flowchart ini menjelaskan tahapan membuat materi yang dilakukan oleh dosen, flowchart ini menggambarkan dimana dosen mulai meletakan materi menggunakan Rinfo Drive berupa Docs, Sheets atau Slides kemudian menyebarkan infonya melalui milis untuk dapat dipelajari dan didiskusikan. 


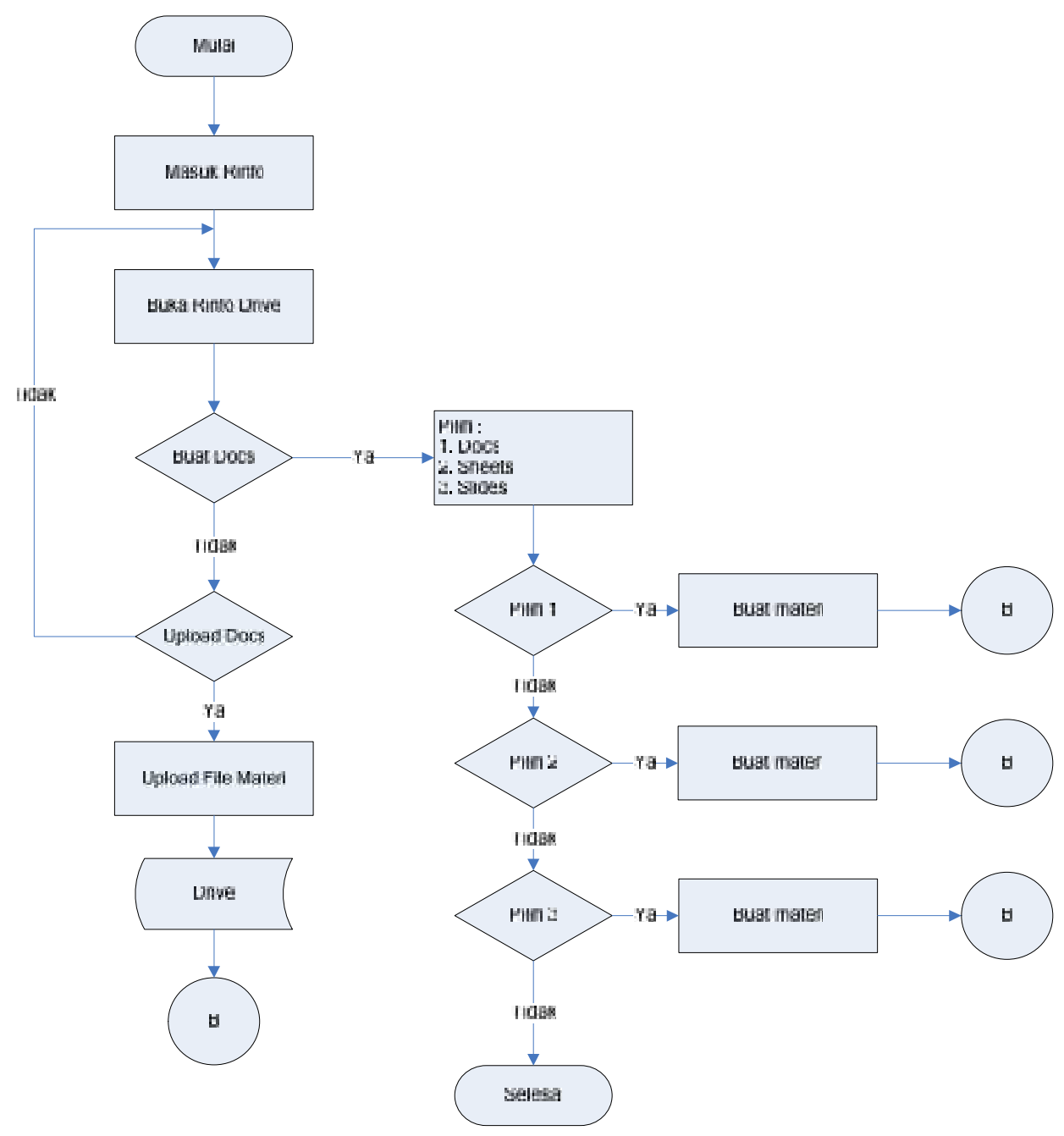

Gambar 4.6

Flowchart Membuat Materi

4. Share Materi.

Flowchart ini menjelaskan tahapan setelah membuat materi pada Rinfo drive yaitu share kepada kelas yang sudah dibuat melalui milis, jika tahapan ini tidak dilakukan maka materi tidak akan dapat di akses oleh mahasiswa. 


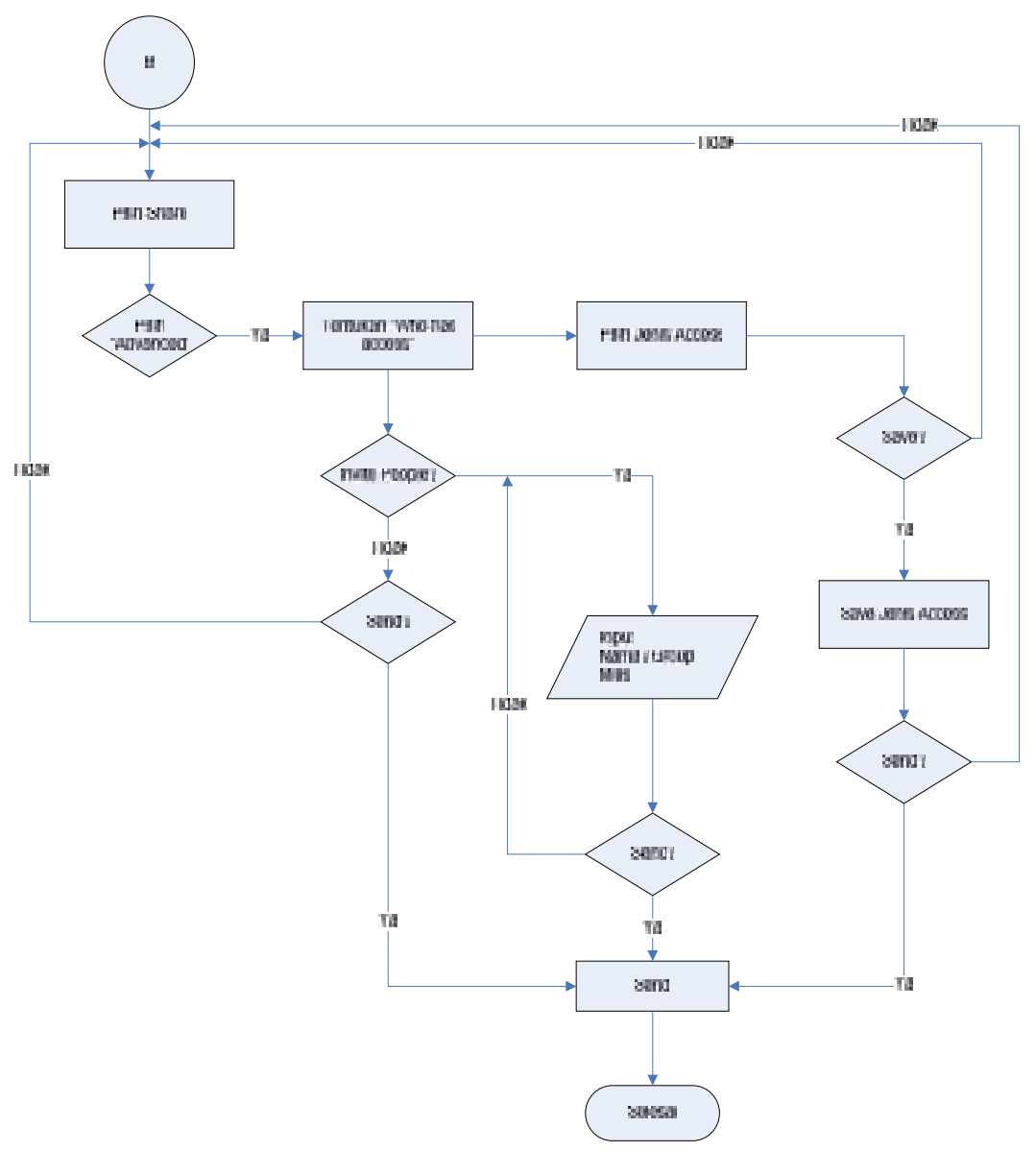

Gambar 4.8

Flowchart Share Materi

\section{IMPEMENTASI}

Implementasi ini terdiri dari beberapa halaman aplikasi yang memiliki fungsi sendiri-sendiri sesuai kebutuhan didalam mendirikan pembelajan berbasis iLearning sehingga tujuan yang hendak di capai dapat terpenuhi dengan baik.

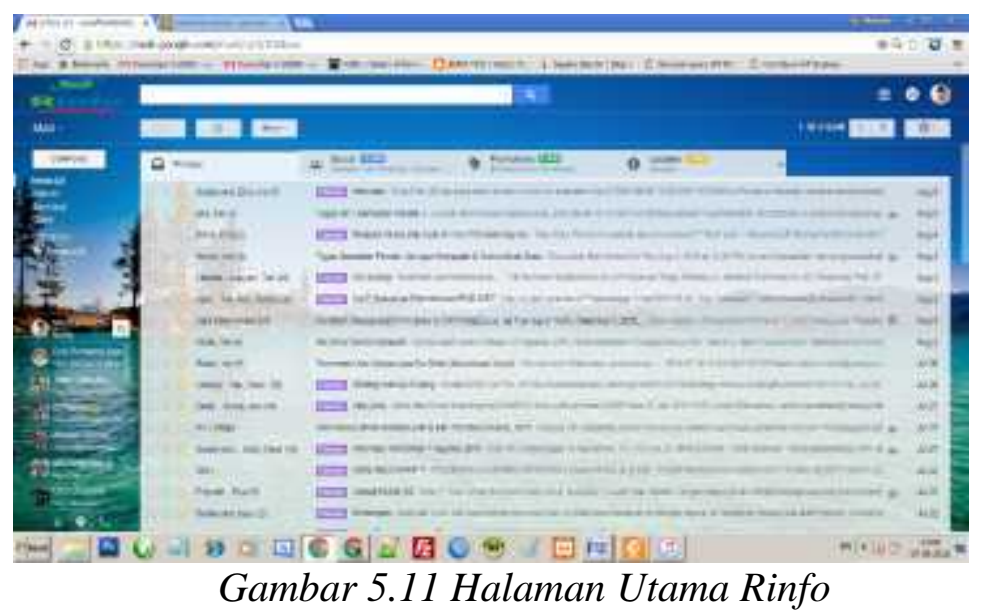


Gambar 5.11 menunjukan tampilan implementasi dari halaman utama rinfo, halaman ini menjadi akses utama didalam memantau semua aktifitas di iLearning baik itu dari Milis class dan juga dari iMe class. Dari sini juga dosen dan mahasiswa bisa melakukan interaksi dan juga aktifitas terkait segala kegiatan yang harus dilakukan didalam iLearning karena semua perangkat e-learning yang ada di sudah saling berintegrasi dan dapat diakses dengan mudah.

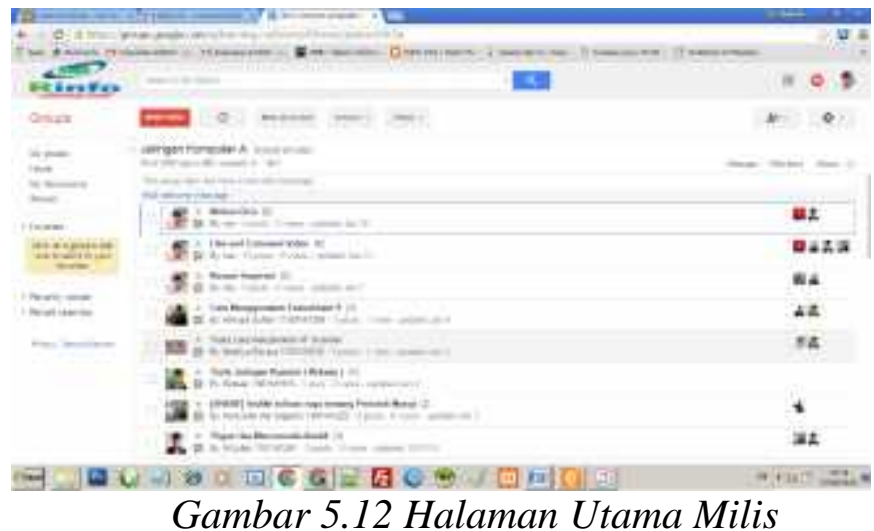

Pada gambar 5.12 menunjukan tampilan dari halaman utama dari Milis class yaitu suatu forum tertutup yang dibuat untuk tempat berdiskusi untuk mahasiswa disetiap kelas sehingga setiap informasi yang akan muat dan atau topic yang akan didiskusikan dapat dikirm dengan mudah dan diakses dengan cepat.

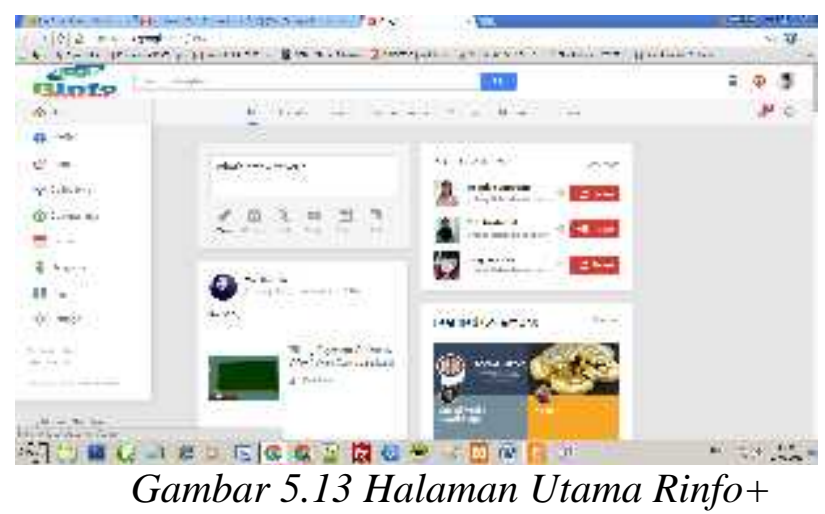

Pada gambar 5.13 adalah tampilan dari Rinfo Plus atau biasa di tulis Rinfo+ merupakan fasilitas yang sudah disediakan oleh google sebagai media social yang sangat popular selalu dimanfaatkan oleh peserta didik yang ada di iLearning untuk mempublis setiap aktifitas berupa gambar dan tautan. 


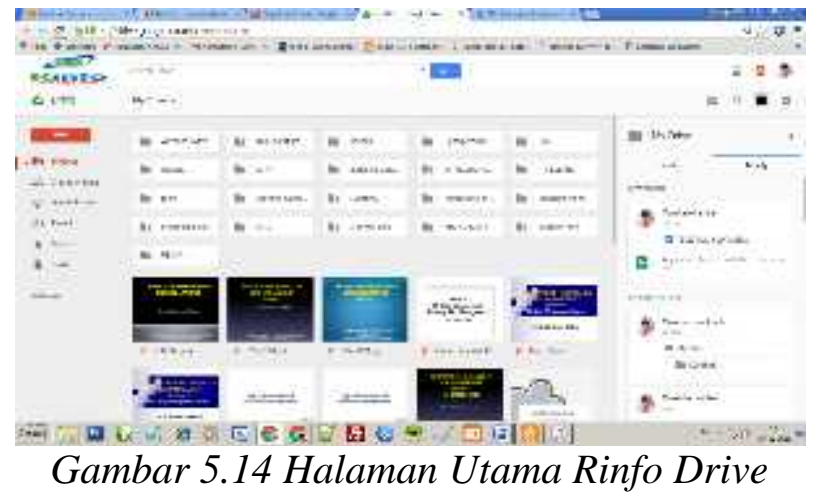

Rinfo Drive fasilitas cloud storage yang selalu dimanfaatkan oleh mahasiswa dan dosen di iLearning untuk menyimpan dokumen-dokumen penting.

\section{KESIMPULAN}

Dengan demikian, dapat disimpulkan bahwa implementasi iLearning pada Universitas Banten Jaya adalah suatu sistem informasi yang berada dalam perangkat lunak berbasis online yang digunakan untuk melakukan batal tambah jadwal kuliah secara online. iLearning akan sangat bermanfaat bagi seluruh mahasiswa pribadi Unbaja dalam melakukan pmbl kuliah seclajaran yang dapat diakses dimana saja hanya dengan menggunakan koneksi internet dan tidak perlu datang ke kampus sehingga dapat meningkatkan mutu pendidikan dan pelayanan yang diberikan kampus terhadap mahasiswa.

\section{SARAN}

Dalam implementasi iLearning membutuhkan koneksi internet untuk mengaksesnya. Serta sistem ini masih terdapat kekurangan salah satunya adalah membutuhkan infrastruktur didalam jaringan internet agar seluruh mahasiswa dapat mengunakan iLearning dengan lancar.

\section{DAFTAR PUSTAKA}

[1] Abdul Kadir. 2014. Pengenalan Sistem Informasi. Yogyakarta: Andi Offset

[2] Andri, Muhammad. 2008. Utilization of Information Technology in the Development of Learning Media. Teknik Elektro, Universitas Gajah Mada. Yogyakarta

[3] Ariani, D.W. 2004. Pengendalian Kualitas Statistik Pendekatan Kuantitatif dan Managemen Kualitas. Yogyakarta: ANDI.

[4] Besterfield, Dale, 2003, Total Quality Manajemen, Edisi tiga, Jakarta : Salemba Empat.

[5] Dwi Siswoyo. (2007). Ilmu Pendidikan. Yogyakarta: UNY Pers.

[6] Henderi, Muhamad Yusup, Yulika Ayu Rantama (2013), Penggunaan Metode iLearning Untuk Meningkatkan Kualitas Pembelajaran di Perguruan Tinggi, Tangerang, STMIK Raharja, CCIT.

[7] Imelda. (2013). Jurnal. Business Intelligence. Manajemen Informatika, Fakultas Teknik, Universitas Komputer Indonesia. Bandung.

[8] Kamus Besar Bahasa Indonesia (Depdikbud, 1983), Cet, 2, hal.179. 
[9] Kotler, Philip. (2000). Manajemen Pemasaran: Analisis, Perencanaan, Implementasi dan Control. Terjemahan. Edisi kedelapan, jilid I, Penerbit Prenhallindo, Jakarta.

[10] Mitchell, T. R. 2009. Research in Organizational Behavior. McGraw-Hill Irwin : New York.

[11] Nana Sudjana, Proses Belajar Mengajar, (Jakarta: Rajawali Press,1989), Cet. Ke-3, h.87.

[12] Panen, P. dkk. 2003. Belajar dan Pembelajaran 1. Jakarta : Universitas Terbuka.

[13] Poerwadarminta, W.J.S. 2005. Kamus Umum Bahasa Indonesia. Jakarta : Balai Pustaka.

[14] Purwanto, 2013. Evaluasi Hasil Belajar. Yogyakarta, Pustaka Pelajar.

[15] Rahardja Untung, (2011) "Definisi iLearning". Raharja Enrichment Centre (REC). Tangerang

[16] Rahardja, Untung, Desrianti, Dewi, Immaniar, Mawadah, Siti, 2011. iBooks Standardisation and Good Practice for Effective Education Methods Insupport of iLearning. Tangerang, CCIT Journal Vol. 5 STMIK Raharja.

[17] Rosyadi, I. 2001. Keunggulan kompetitif berkelanjutan melalui capabilitiesbased competition: Memikirkan kembali tentang persaingan berbasis kemampuan. Jurnal BENEFIT, vol. 5, No. 1, Juni 2001. Surakarta: Fakultas Ekonomi Universitas Muhammadiyah Surakarta.

[18] Santyasa, I. W. (2011). Pembelajaran inovatif. Bahan ajar. Singaraja: Universitas Pendidikan Ganesha.

[19] Sugandi, Achmad, dkk. 2000. Belajar dan Pembelajaran. Semarang: IKIP PRESS.

[20] Sugandi, Achmad, dkk. 2004. Teori Pembelajaran. Semarang:UPT MKK UNNES.

[21] Surya, M. (2003). Psikologi Pembelajaran dan Pengajaran. Bandung: Yayasan Bhakti Winaya.

[22] Sutikno, M.S. 2007. Mengagas Pembelajaran Efektif dan Bermakna. Mataram: NTP Press.

[23] Wahyuni, D. U. 2008. Pengaruh Motivasi, Persepsi, dan Sikap Konsumen TerhadapKeputusan Pembelian Sepeda Motor Merek Honda di Kawasan Surabaya Barat. (http://www.petra.ac.id/puslit/journals).

[24] Yamin, M. 2007.Kiat Membelajarkan Siswa . Jakarta: Gaung Persada 